\title{
Computation of Single Beam Echo Sounder Signal for Underwater Objects Detection and Quantification
}

\author{
Henry M. Manik \\ Department of Marine Science and \\ Technology Faculty of Fisheries and \\ Marine Sciences \\ Bogor Agricultural University (IPB) \\ Kampus IPB Darmaga Bogor \\ Indonesia
}

\author{
Asep Mamun \\ Department of Marine Science and \\ Technology Faculty of Fisheries and \\ Marine Sciences \\ Bogor Agricultural University (IPB) \\ Kampus IPB Darmaga Bogor \\ Indonesia
}

\author{
Totok Hestirianoto \\ Department of Marine Science and \\ Technology Faculty of Fisheries and \\ Marine Sciences \\ Bogor Agricultural University (IPB) \\ Kampus IPB Darmaga Bogor \\ Indonesia
}

\begin{abstract}
Underwater Acoustic methods have been extensively used to locate and identify marine objects. These applications include locating underwater vehicles, finding shipwrecks, imaging sediments and imaging bubble fields. Ocean is fairly transparent to sound and opaque to all other sources of radiation. Acoustics technology is the most effective tool for monitoring this environment because of the sound's ability to propagate long distance in water. We used single beam echo sounder to discriminate underwater objects. Development of the algorithm and applied it to detect and quantify underwater object such as fish, sea grass, and seabed. We found the detected target has different backscatter value.
\end{abstract}

Keywords—single beam; echo sounder; backscattering; algorithm

\section{INTRODUCTION}

Ocean acoustics is the use of sound to measure the distribution and abundance of fish and other aquatic organisms. The physics of sound propagation in seawater is well understood $[1 ; 2]$ and an appreciation thereof is helpful to interpret acoustics data correctly. Fortunately, analysis software performs most calculations; however, fish are complex sound scatterers, and theory developed for simple bodies such as spheres is only partly applicable $[3 ; 4 ; 5 ; 6]$. Therefore, practical experience with fisheries surveys is also important. A scientific echo sounder consists of a transceiver (which includes transmitting and receiving electronics), a transducer, and a recording device, which is usually a computer. The computer controls operation of the echo sounder $[7 ; 8 ; 9 ; 10 ; 11]$. The transceiver sends a short electric signal to the transducer, which transforms this electric energy to a sound pulse (also called a ping). Ease of use the time until the next transmission, the transducer "listens" for any returning echoes and back transforms them to electric voltages that are digitized by the transceiver and recorded, typically on the computer hard drive $[12 ; 13 ; 14 ; 15]$.

The main considerations when selecting an echo sounder are frequency, beam width, and type of transducer. Transducer configurations can be single-beam, dual-beam, split-beam or multi beam[16;17;18;19;20]. A single-beam system provides no information on target location, thereby precluding direct estimation of target strength (TS). Target strength distributions must be estimated statistically when using single-

beam systems. To address this problem, we develop the algorithm and applied it to detect and quantify the receiving signal using single beam echo sounder.

\section{METHODOLOGY}

\section{A. Development of Sonar Equation for Single Beam}

The sonar equation deals with working relationship that tie together the effects of the medium, the target, and the equipment. For single beam echo sounder, the received signal are computed using

$$
T S=20 \log (\text { counts })-S L-R S+P S+T L+T V G
$$

where $T S$ is target strength, $S L$ is source level, $R S$ is receiving sensitivity, $P S$ is power setting, $T L$ is transmission loss due to absorption and geometrical spreading of acoustic wave, and $T V G$ is time varied gain.

Counts $=$ DN $/ 255$

$D N$ is digital number of signal with 8 bit sampling. To calculate the beam pattern, the equation 1 is developed by

$T S=20 \log ($ Count $)-S L-R S+P S+T L+T V G+C e+C$

$C e=10 \log (c \tau \psi / 2)$

$c$ is sound speed, $\tau$ is pulse width, $\psi$ is equivalent beam angle for volume backscattering and $\mathrm{C}$ is correction factor for acoustics instruments.

To calculate the fish abundance, the volume backscattering $(\mathrm{SV})$ is calculated by

$S V=20 \log ($ Count $)-S L-R S+P S+T L+T V G+C e+C+V$

where $V$ is volume sampling of acoustic beam

$V=c \times \tau / 2 \times \psi \times R^{2}$ 
$R$ is range.

Algorithm design for single beam acoustic processing is shown in Figure 1.

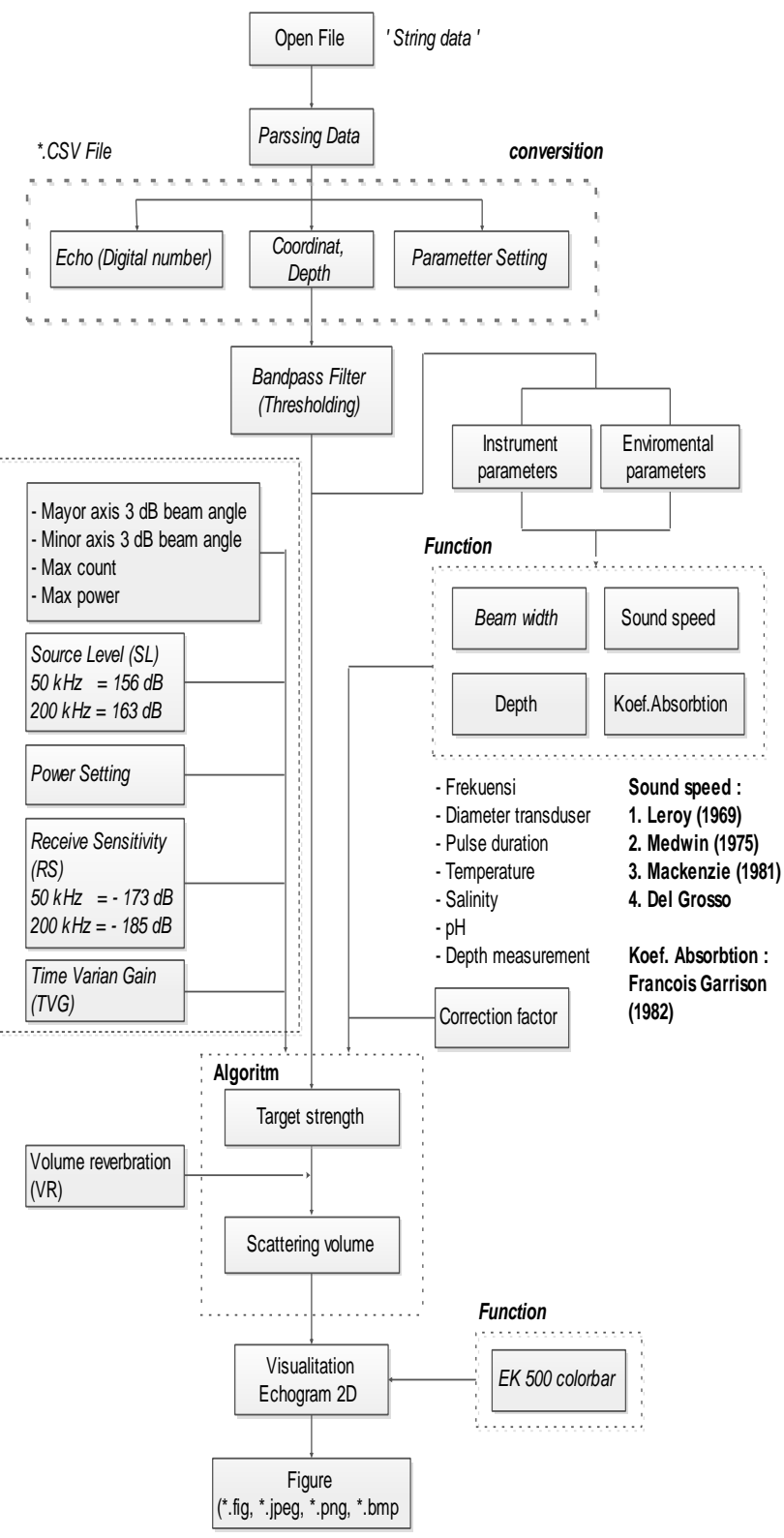

Fig. 1. Algorithm design for single beam acoustic processing

\section{RESULTS AND DISCUSSION}

\section{A. Acoustics Calibration}

Scientific echo sounders must be calibrated at regular intervals to ensure consistently high data quality. Calibration involves measuring volume backscattering ( $S V)$ and TS of standardized (known TS) copper or tungsten carbide spheres located on the main axis and in the far field of the transducer (Figure 2). Calibration should be done under the conditions and field settings of the survey to provide whole-system calibration that combines source-level and receiver sensitivity into one correction factor.
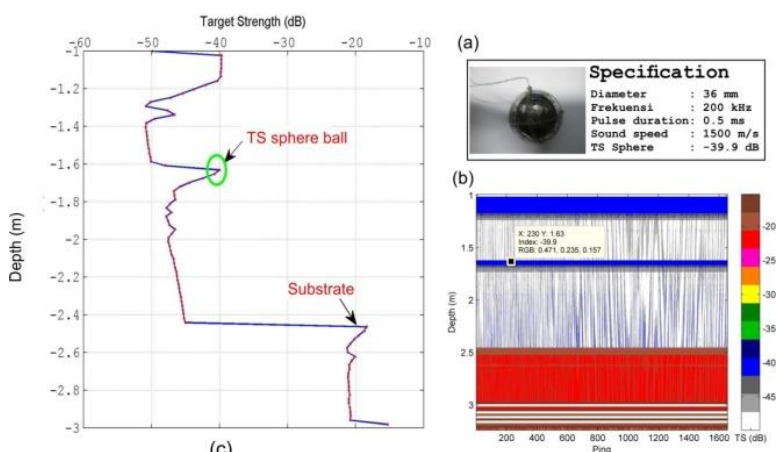

Fig. 2. Acoustic calibration using sphere ball

TABLE I. COMPARISON USING MEASUREMENT AND THEORETICAL VALUE

\begin{tabular}{|l|l|c|c|}
\hline & & Measurement & Theory \\
\hline \multirow{2}{*}{$\mathrm{N}$} & valid & 1654 & 1654 \\
\cline { 2 - 4 } & missing & 0 & 0 \\
\hline Mean & -39.9 & -39.9 \\
\hline Median & -39.9 & -39.9 \\
\hline Modus & -39.9 & -39.9 \\
Std. Deviation & 0.13 & 0.00 \\
\hline Variance & 0.02 & 0.00 \\
Minimum & -40.2 & -39.9 \\
\hline Maximum & -39.7 & -39.9 \\
\hline
\end{tabular}

\section{B. Application of Acoustic Algorithm}

The application of algorithm using single beam sounder are compared using another system of split beam method for underwater vegetation, fish and seabed. Figure 3 show the backscatter intensity ( $\mathrm{Sv})$ of seagrass. Table 2 shows data comparison using this system.

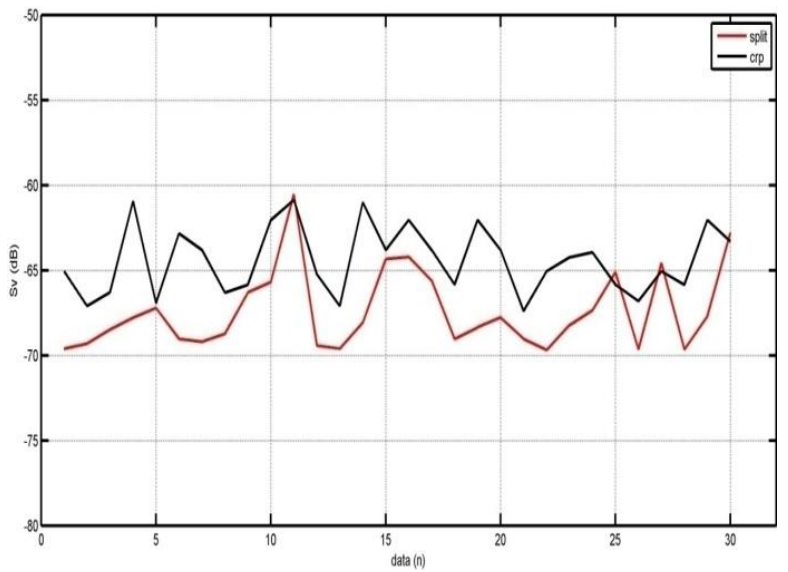

Fig. 3. Backscattter intensity of seagrass (rea line for single beam, black line for split beam).

Table 2 shows the backscattering intensity for single beam ranges from $-60,5 \mathrm{~dB}$ to -69.7 , for split beam ranged from $-60,8$ to $-67,40 \mathrm{~dB}$ with the average are $-67,4 \mathrm{~dB}$ and $-66,4 \mathrm{~dB}$, respectively. Figure 4 shows the backscatter intensity from coral reef and Table 3 is the statistical vale of the results. Backscatter intensity for coral reef using single beam ranged from $-31 \mathrm{~dB}$ to $-33 \mathrm{~dB}$, while using split beam ranged from $28 \mathrm{~dB}$ to $-35 \mathrm{~dB}$. 
TABLE II. COMPARISON Single BeAm AND SPlit BeAm For SEAgRass DETECTION

\begin{tabular}{|l|l|c|c|}
\hline & & Single beam & Split beam \\
\hline \multirow{2}{*}{$\mathrm{N}$} & valid & 30 & 30 \\
\cline { 2 - 4 } & Missing & 0 & 0 \\
\hline Mean & -67.4 & -64.4 \\
\hline Median & -68.2 & -64.6 \\
\hline Std. Deviation & 2.33 & 2.01 \\
\hline Variance & 5.44 & 4.03 \\
\hline Minimum & -69.7 & -67.4 \\
\hline Maximum & -60.5 & -60.8 \\
\hline
\end{tabular}

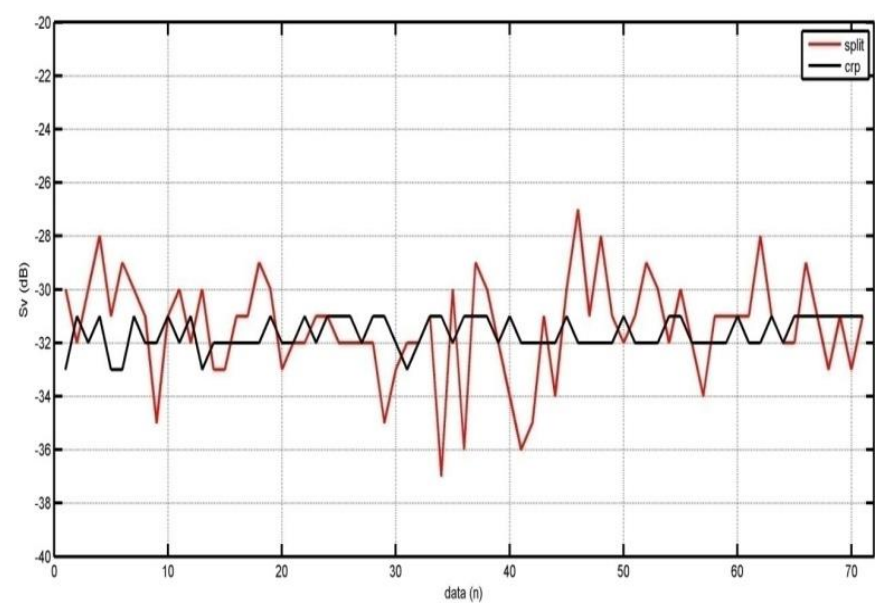

Fig. 4. Backscatter intensity of coral reef using single and split beam

TABLE III. COMPARISON OF Single BeAm AND SPlit BeAm For CoRAL REEF DETECTION

\begin{tabular}{|l|c|c|}
\hline & Single beam & Split beam \\
\hline N valid & 70 & 70 \\
\hline \multicolumn{1}{|c|}{ Missing } & 0 & 0 \\
\hline Mean & -31.7 & -31.4 \\
\hline Median & -32.0 & -31.0 \\
\hline Mode & -32.0 & -32.0 \\
\hline Std. Deviation & 0.69 & 1.61 \\
\hline Minimum & -33.0 & -35.0 \\
\hline Maximum & -31.0 & -28.0 \\
\hline
\end{tabular}

Figure 5 shows backscatter intensity from mud bottom using single beam and split beam with the statistical value in Table 4.

Table 4 shows backscatter intensity for mud bottom using single beam ranged from $-30.0 \mathrm{~dB}$ to $-28.4 \mathrm{~dB}$ and using split beam ranged from -32.3 to $-25.1 \mathrm{~dB}$.

Figure 6 shows the backscatter intensity from sand using single and split beam. Range of intensity from $-19.6 \mathrm{~dB}$ to $19.8 \mathrm{~dB}$ using single beam and $-25.1 \mathrm{~dB}$ to $-16.7 \mathrm{~dB}$ (Table 5).

Figure 7 and Table 6 shows the comparison of backscatter intensity using single and split beam for fish. The backscatter intensity of fish range from $-58.3 \mathrm{~dB}$ to $-49.0 \mathrm{~dB}$ for single beam and for split beam range from -58.3 to $-45.8 \mathrm{~dB}$.

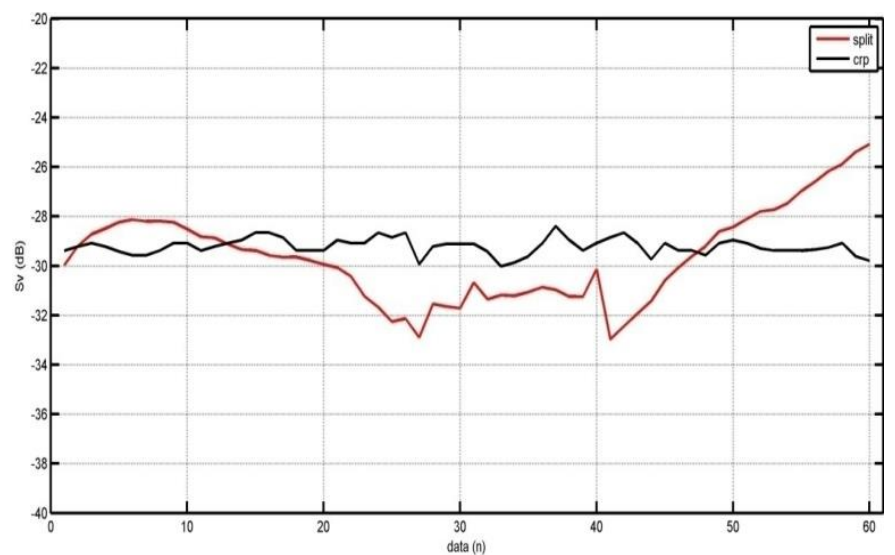

Fig. 5. Backscatter intensity of mud bottom using single and split beam

TABLE IV. Comparison Single Beam and Split Beam For Mud ВОТTOM

\begin{tabular}{|c|l|c|c|}
\hline & & Single beam & $\begin{array}{c}\text { Split } \\
\text { beam }\end{array}$ \\
\hline \multirow{2}{*}{$\mathrm{N}$} & Valid & 60 & 60 \\
\cline { 2 - 4 } & Missing & 0 & 0 \\
\hline Mean & -29.2 & -29.6 \\
\hline Median & -29.2 & -29.6 \\
\hline Std. Deviation & 0.33 & 1.86 \\
\hline Variance & 0.1 & 3.5 \\
\hline Minimum & -30.0 & -32.3 \\
\hline Maximum & -28.4 & -25.1 \\
\hline
\end{tabular}

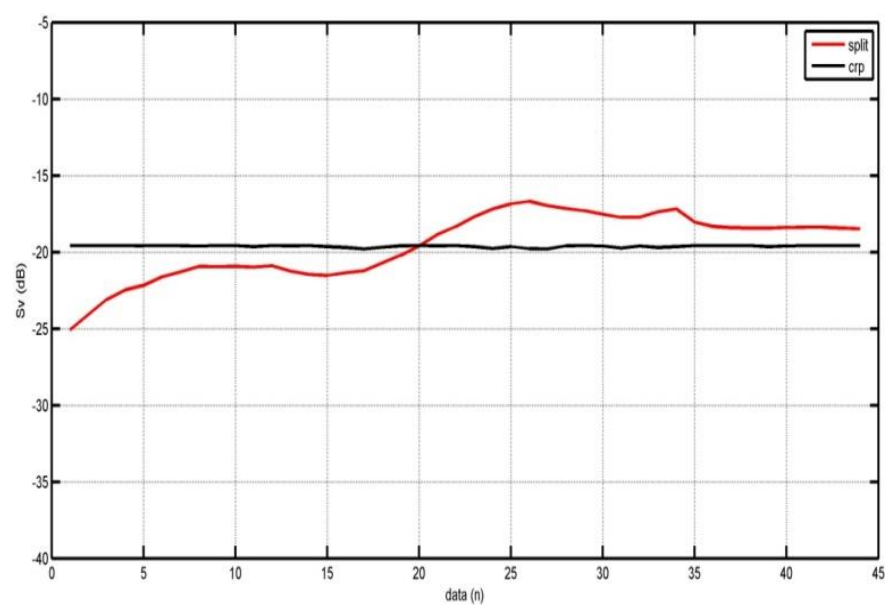

Fig. 6. Backscatter intensity from sand bottom

TABLE V. COMPARISON OF SINGLE AND SPLIT BEAM FOR SAND BOTTOM

\begin{tabular}{|c|l|r|r|}
\hline & \multicolumn{1}{|c|}{$\begin{array}{l}\text { Single } \\
\text { beam }\end{array}$} & \multicolumn{1}{c|}{ Split beam } \\
\hline \multirow{2}{*}{$\mathrm{N}$} & Valid & 44 & 44 \\
\cline { 2 - 4 } & Missing & 0 & 0 \\
\hline Mean & -19.6 & -19.5 \\
\hline Median & -19.6 & -18.5 \\
\hline Std. Deviation & 0.06 & 2.12 \\
\hline Variance & .004 & 2.498 \\
\hline Minimum & -19.8 & -25.1 \\
\hline Maximum & -19.6 & -16.7 \\
\hline
\end{tabular}




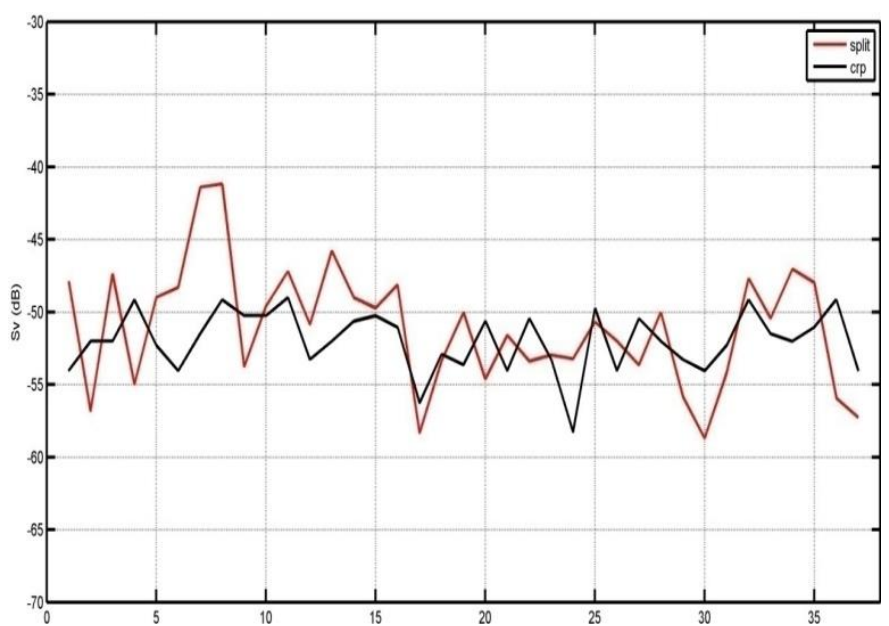

Fig. 7. Backscatter intensity from fish using single and split beam

TABLE VI. COMParison OF Single BeAm AND SPlit BeAm For Fish

\begin{tabular}{|c|l|r|r|}
\hline & \multicolumn{1}{|c|}{$\begin{array}{l}\text { Single } \\
\text { beam }\end{array}$} & Split beam \\
\hline \multirow{2}{*}{$\mathrm{N}$} & Valid & 37 & 37 \\
\cline { 2 - 4 } & Missing & 0 & 0 \\
\hline Mean & -51.9 & -51.4 \\
\hline Median & -52.0 & -51.5 \\
\hline Std. Deviation & 2.1 & 2.9 \\
\hline Variance & 4.4 & 8.5 \\
\hline Minimum & -58.3 & -58.3 \\
\hline Maximum & -49.0 & -45.8 \\
\hline
\end{tabular}

\section{CONCLUSION}

We had developed algorithm of processing signal using single beam echo sounder. The application of this algorithm had applied to detect underwater objects such as coral reef, fish, seagrass, mud and sand bottom. We also compare the single beam echosounder result with established split beam acoustics method. From the result of comparison we conclude that backscatter intensity measured using developed algorithm using single beam is nearby the established acoustic system using split beam. Future work is to examine this algorithm in the real condition in ocean field, simultaneously with split or multi beam method. For quantitative purpose, single beam acoustic is easy to operate and classification of detected underwater target is possible.

\section{ACKNOWLEDGMENT}

The authors would like to thank Ocean Acoustics Laboratory of Department of Marine Science and Technology Faculty of Fisheries and Marine Sciences of Bogor Agricultural University (IPB) research members and students for data collection.

\section{REFERENCES}

[1] Au, W. W. L., and Benoit-Bird, K. J. (2008). "Broadband backscatter from individual Hawaiian mesopelagic boundary community animals with implications for spinner dolphin foraging," J. Acoust. Soc. Am. 123 ,

2884-2894.

[2] Benoit-Bird, K. J., Gilly, W. F., Au, W. W. L., and Mate, B. (2008).

[3] "Controlled and in situ target strengths of the jumbo squid Dosidicus gigas and identification of potential acoustic scattering sources," J. Acoust. Soc. Am. 123, 1318-1328.

Iida, K., Takahashi, R., Tang, Y., Mukai, T., and Sato, M. (2006).

"Observation of marine animals using underwater acoustic camera," Jpn. J. Appl. Phys., Part 1 45, 4875-4881.

[4] Jones, B. A., Lavery, A. C., and Stanton, T. K. (2009). "Use of the distorted wave Born approximation to predict scattering by inhomogeneous objects: Application to squid.” J. Acoust. Soc. Am. 125, 73-88.

[5] Kang, D., Iida, K., Mukai, T., and Kim, J. (2006). "Density and sound speed contrasts of the japanese common squid Todarodes pacificus and their influence on acoustic target strength," Fish. Sci. 72, 728-736.

[6] Kang, D., Mukai, T., Iida, K., Hwang, D., and Myoung, J. (2005). “The influence of tilt angle on the acoustic target strength of the Japanese common squid (Todarodes pacificus)," ICES J. Mar. Sci. 62, 779-789.

[7] Kaipio, J. \& Somersalo, E. 2005 Statistical and Computational Inverse Problems, Springer Science+Business Media, New York.

[8] Lavery, A. C., Chu, D., and Moum, J. N. (2010). "Measurements of acoustic scattering from zooplankton and oceanic microstructure using a broadband echosounder," ICES J. Mar. Sci. 67, 379-394.

[9] Lavery, A. C., and Ross, T. (2007). "Acoustic scattering from doublediffusive microstructure," J. Acoust. Soc. Am. 122, 1449-1462.

[10] Lavery, A. C., Stanton, T. K., McGehee, D. E., and Chu, D. (2002). "Threedimensional modeling of acoustic backscattering from fluid-like zooplankton,” J. Acoust. Soc. Am. 111, 1197-1210.

[11] Lawson, G. L., Wiebe, P. H., Ashjian, C. J., Chu, D., and Stanton, T. K. (2006). "Improved parameterization of antarctic krill target strength models," J. Acoust. Soc. Am. 119, 232-242.

[12] Lee, W. J., Lavery, A. C., and Stanton, T. K. (2010). "Interpretation of the compressed pulse output for broadband acoustic scattering from inhomogeneous weakly scattering objects," J. Acoust. Soc. Am. 128, 2460.

[13] Medwin, H., and Clay, C. S. (1998). Fundamentals of Acoustical Oceanography (Academic Press, San Diego, CA), pp. 348-401.

[14] Mooney, T. A., Lee, W.-J., and Hanlon, R. T. (2010). "Long-duration anesthetization of squid (Doryteuthis pealeii)," Mar. Freshwater Behav. Physiol. 43, 297-303.

[15] Urick, Robert J., Principles of Underwater Sound 3rd Ed. (McGraw Hill, New York), (1983)

[16] Simmonds, J., and D. MacLennan. 2005. Fisheries acoustics: theory and practice. Blackwell, Oxford, UK

[17] Stanton, T. K. 2009. Broadband acoustic sensing of the ocean. Journal of the Marine Acoustical Society ofJapan 36:95-107.

[18] Stanton, T. K., D. Chu, J. M. Jech, and J. D. Irish. 2010. New broadband methods for resonance classification and high-resolution imagery of fish with swim bladders using a modified commercial broadband echosounder. ICES Journal of Marine Science 67:365-378.

[19] Stanton, T. K. \& Chu, D. 2008 'Calibration of broadband active acoustic systems using a single standard spherical object', Journal of the Acoustical Society of America, vol. 124 (1), July 2008.

[20] Quintino, V., Freitas, R., Mamede, R., Ricardo, F., Rodrigues, A. M., Mota, J., Pe'rez-Ruzafa, A' ., and Marcos, C. 2010. Remote sensing of underwater vegetation using single-beam acoustics. - ICES Journal of Marine Science, 67: 594-605. 